Education Today

Manuscript Number:

Title: Turning a crisis into an interactive drama: The introduction of a 'Clickers Theatre' in nurse education.

Article Type: Big Ideas

Section/Category: Big Ideas

Corresponding Author: Mr. James John Wilson, MSc

Corresponding Author's Institution: University of Southampton

First Author: James John Wilson, MSC

Order of Authors: James John Wilson, MSc; Sandra Walker

Manuscript Region of Origin: UNITED KINGDOM 
Cover Letter

Covering letter

Dear Editor

I wish to detail the authorship contributions:

First author: James Wilson

Second author: Sandra Walker

Both authors have agreed that this is the correct order of authorship.

There are no further matters for the editors to consider. 
Supporting documentation

TURNING A CRISIS INTO AN INTERACTIVE DRAMA: AN INTRODUCTORY PAPER OF A 'CLICKERS THEATRE' IN NURSE EDUCATION.

Word Count: 1980 (excluding references)

Authors:

James Wilson

Lecturer in mental health

Faculty of Health Sciences, University of Southampton. Southampton

Tel: 02380597894

Email: j.wilson@soton.ac.uk

\section{Sandra Walker}

Lecturer in mental health

Faculty of Health Sciences, University of Southampton. Southampton

Tel: 02380597979

Email: s.c.walker@soton.ac.uk

Funding Source Declaration: None

Author Agreement/Declaration: James Wilson \& Sandra Walker certify that the authors have seen and approved the final version of the manuscript being submitted. We warrant that the article is:

- The authors' original work

- Has not received prior publication

- Is not under consideration for publication elsewhere. 
TITLE: Turning a crisis into an interactive drama: The introduction of a 'Clickers Theatre' in nurse education.

\section{Introduction}

The aim of the project was to create an interactive, theatrical-based method which promoted the service user voice in tandem with clinical decision making in the classroom. The purpose of this work was to portray 'big picture care' by demonstrating the complexity involved in clinical decision making. To develop nurses as autonomous clinical decision makers, pre-registration education and training programmes need to incorporate an educational agenda that supports the development of the prerequisite intellectual and cognitive skills that are needed in order to manage complex information to make judgements (Banning 2007). Dealing with such a multifaceted subject, (Crookes et al. 2013) recognises that nurse educators have the task of creating meaningful learning experiences that assist students enhance their own understanding of the impact that their clinical decision making will have on the patient journey while at the same time embedding habits of reflection, compassion and making sense of critical observation.

This paper introduces an innovative type of interactive theatre entitled 'Clickers theatre' which provides the student audience with an electronic student response system (SRS) while combining a story written in a 'choose your own adventure' (CYOA) format along with the production of a theatrical play. This creates a visual spectacle where at pre-determined points the audience decide how the actors in the play should proceed. The SRS clinical decisions moves the play along in a nonlinear direction revealing unexpected consequences and alternative endings. This paper discusses a collaboration involving mental health service users, student nurses, NHS staff and University staff.

\section{What is Clickers theatre?}

The essentials of a clicker's theatre combine the use of three core mechanisms:

1. A story written as a 'choose your own adventure' (CYOA)

2. The creation and delivery of a theatrical production

3. The use of an electronic student response system (SRS)

\section{Clickers theatre and the service user voice}

A clicker's theatre begins by selecting a narrative which is adapted into a CYOA story. It is then transformed it into an interactive theatrical play using the SRS. The storyline in this project was voluntarily donated by a member of the human library (Humanlibrary.org 2016) who had experience as a service user. The project aimed to establish partnership working, co-design and authenticity as the 'human book' was present throughout the design, rehearsal and presentation of the play. Crawford et al. (2002) recognises that service users and carers are experts in their experience who often have a good knowledge of services and how the system works. People who have used services bring their own perspective about treatment and care which influenced the formation of the play. The incorporation of a service user led narrative can help challenge traditional assumptions yet the Welsh Assembly Government (2008) recognised that service users and carers who find themselves in classrooms often do so with little or no organised training to support. Tevendale (2015) states that the storytelling approach in nurse education has recognised advantages however the National Leadership and Innovation Agency for Healthcare (2010) showed that a classroom-based session where a lone service user is required to present orally can result in difficulties. The service user may not be able to get their point of view across and therefore feel that time and effort has been wasted. Other challenges have included feelings of confusion or frustration and lack of confidence at presenting to groups. A clickers theatre approach can overcomes some key issues for instance the theatrical approach creates a safer educational 'distance' between the student and the service user. 
TITLE: Turning a crisis into an interactive drama: The introduction of a 'Clickers Theatre' in nurse education.

It bridges the balance of the pathos experienced by a student who can instead feel emotionally connected to the whole 'story' rather than focus on the oratory abilities of a brave service user sharing their deeply personal monologue. At all times it was essential for us to work sensitively with the story that had been provided and the engagement of the human book was identified as the beating heart of this project.

\section{The 'choose your own adventure'}

Combining the use of the SRS and a CYOA format means that the audience can participate and affect the outcome of the play. The student observes the main characters in the story and will guide them down various paths through the use of the SRS. As the audience follows the plot they are often given certain choices that have to be made as the play progresses. The opening scenes are observed by the audience then one of the characters in the play is presented with a dilemma and needs to make a 'choice' about the situation they are in. The combined live theatre/CYOA and SRS empowers and engages audiences to consider their democratic vote as their majority decision determines the direction of the play. After the play, a facilitated discussion opens a dialogue between the actors and audience about the issues that emerged.

\section{Clickers theatre and the student response system}

The SRS system used in this project was developed by Turning Technologies. At the start of the session, each member of the audience was provided with a 'ResponseCard RF Accessibility' and provided with the instructions on how their vote would decide the direction of the play. The multiple choices that the audience members could make were pre-loaded onto the PowerPoint presentation using the TurningPoint software system. Once the audience had voted, the visual display of the results illuminate the disparity of decisions despite experiencing the same play. This variance is reflected back to the audience in the post-play discussion which highlights the diversity and subjective approach of clinical decision making.

The SRS was incorporated to stimulate a sense of democratic engagement which encourages students to critique what they are witnessing, decide what they think and take a stand by voting. There is also an emotional component as students empathise with the characters whose fates are on the line. The use of the SRS in nurse education in itself is not new. In the nursing literature the advantages include increasing attentiveness to lectures, clarifying information, providing immediate feedback, promoting an anonymous environment, increasing student participation, and encouraging critical thinking (Fifer 2012). The SRS is mostly deployed in a style described by Porter and Tousman (2010) as 'question driven instruction' which aims to demonstrate better understanding of the theoretical material post session. This project offers a novel usage of the SRS with a shift in education focus away from an instructional and more towards an experiential learning style. While the engaging nature of the theatrical experience is maintained via the performance, it is the additional anticipation that a vote is imminent which combines to create a heightened sense of awareness among a student audience. Deploying the SRS facilitates an interactive component without the student's requirement to be directly involved on the stage. Using interactive theatre and the SRS encouraged a less passive approach than watching a more traditional theatre experience (Boal 2002). Other interactive teaching methods include role play (Van Ments 1999), clinical simulation or as a spect-actor in a theatre of the oppressed forum theatre (Boal 2002). This type of pedagogy is deliberately pre-designed to provoke participants to enter into the action directly in the stage area. The student audience report strong reactions to extremely interactive sessions and can vary to from the feeling of fear described by Day (2002) like they are stepping into a 'bullpit' to embracing the learning potential of gaining exposure to 'near-real' events in a live and safe 
TITLE: Turning a crisis into an interactive drama: The introduction of a 'Clickers Theatre' in nurse education.

classroom setting (Freire 1983). In recent years, educators in health care have begun to re-examine the use of various theatre-based approaches to learning (Deloney and Graham 2003; Lepp et al. 2003; Ekebergh et al. 2004; McClimens and Scott 2007; McAlinden 2010; Oflaz et al. 2011; Middlewick et al. 2012; Wilson 2013; D'Ardis 2014). Interest continues to evolve in theatre-based sessions as Middlewick et al. (2012) states that it is a useful tool in allowing the rehearsal of difficult situations that are challenging to engage in a traditional lecture format.

\section{Clickers theatre and Student learning opportunities}

This project recruited volunteer senior student nurses with the opportunity to be the actors in the play. The volunteers were led through a rehearsal period aimed at building trust as a team, providing a safe, creative space to build their confidence in being able to present an authentic experience to a watching audience. The play was presented to the peers of the student actors and offered a 'students teaching students' opportunity which improved their development of the course content by gaining a deeper understanding of the characters. By volunteering, the student actors enhanced their employability skills as they had the opportunity to nurture communication skills, teamwork, leadership, confidence and respect for peers which are vital to developing professionalism early in any nursing career (Krych et al. 2005). The human book was present throughout to offer insights to the story which informed the student actors understanding and portrayal of the character they were playing. This invaluable contribution promoted the 'service user as teacher'.

\section{Clickers theatre and Clinical decision making}

Clinical decisions are a natural outcome of any assessment in healthcare and ideally should always involve the person concerned. In practice, particularly in mental healthcare this is often still not the case and decisions are made, then relayed to the individual as a fait accompli (Walker 2013). Clinical decisions are made from a combination of knowledge of the resources available; the needs and wishes of the individual concerned; the knowledge and experience of the nurse and evidenced based information. The project blended legitimate evidence based interventions while providing the audience with the wider story and context, portrayed through the lens of the service user. The play is able to highlight what occurs during the times when the clinician is absent and reveal hidden factors. This presented as a medium for investigation into sensitive subjects where students explore the range of good and bad in a situation, in detail without risk to patients. By combining service user narratives with a clickers theatre concept engages and exposes health care audiences to engage with the complex emotional, interpersonal and psychological dynamics that arise in making decisions in practice, many of which are difficult to fully convey in more traditional forms of dissemination (e.g. didactic lectures). Students described difficulties between discerning their emotional struggle and what they think is right. During the session, students are posed challenging questions, make heartfelt comments and collectively reach decisions in a classroom environment where freedom to speak their minds on intellectual, ethical, moral and legal issues is encouraged. (Edmiston 2000)

\section{Clickers theatre: Next steps}

As with all new pedagogical adventures into the unfamiliar, the clicker's theatre concept needs time to develop and mature. Although the entire project had a zero financial cost, the main resource required was time. The dedication of time included meeting and establishing a partnership with the service user; gathering and editing the narrative into a CYOA play; a recruitment phase to encourage student nurses to become actors; an intensive two day rehearsal with the actors; skilful leadership to offer clear yet gentle direction to ensure that the group worked together so that they were authentic and flawless in the portrayal of the numerous directions that CYOA play could take. 
TITLE: Turning a crisis into an interactive drama: The introduction of a 'Clickers Theatre' in nurse education.

Further research into this area will decide whether the investment of time is matched with the learning benefits for student learners.

\section{Conclusion}

There are clear benefits to the clicker's theatre concept. Drawing upon the powerful, engaging and emotive educational value of a theatrical experience that is influenced by real events presents nursing students with a storytelling mechanism that enables engagement that is neither passive nor requires direct intervention by entering the scene. This interactive technique is a natural synergy and builds a dramatically interesting world influenced by real patient narratives. The inclusion of an SRS provides students audiences to take their time to pause and debate the decisions with each other before voting.... luxury not always afforded in the maelstrom of clinical practice.

\section{References}

Banning M (2007) A review of clinical decision making: models and current research. Journal of clinical nursing (Feb 28)

Boal A (2002) Games for actors and non-actors (2nd Edition). London: Routledge

Crawford M, Rutter D and Manley C (2002) Systematic review of involving patients in the planning and development of health care. British Medical Journal (325): 1263-1265

Crookes K, Crookes P and Walsh K (2013) Meaningful and engaging teaching techniques for student nurses: A literature review. Nurse Education Today (13): 239-243

D'Ardis M (2014) Forum theatre for practice simulation and skills development in nurse education: A student's perspective. Nurse Educ Today 34(8): 1136-7

Day L (2002) 'Putting yourself in other peoples shoes': the use of forum theatre to explore refugee and homeless issues in schools. Journal of moral education 31(1): 21-34

Deloney LA and Graham CJ (2003) Wit: using drama to teach first-year medical students about empathy and compassion. Teach Learn Med 15(4): 247-51

Edmiston B (2000) Drama as ethical education. Research in Drama Education 5(1): 63-84

Ekebergh M, Lepp M and Dahlberg K (2004) Reflective learning with drama in nursing education--a Swedish attempt to overcome the theory praxis gap. Nurse Educ Today 24(8): 622-8

Fifer $P$ (2012) Student perception of clicker usage in nursing education. Teaching and learning in nursing (7): 6-9

Freire P (1983) Education for critical consciousness. New York: Continuum

Humanlibrary.org (2016) Dont judge a book by its cover. Available from: http://humanlibrary.org/]

Krych A, March C, Ross B, Peake P and Carmichael S (2005) Reciprocal Peer Teaching: Students Teaching Students in the Gross Anatomy Laboratory. Clinical anatomy (18): 296-301

Lepp M, Rinsberg K, Holm A and Sellersjo G (2003) Dementia - involving patients and their caregivers in a drama programme: the caregivers' experiences. Journal of clinical nursing 12: 873-881

McAlinden O (2010) Explaining suicide the role of drama. Mental health practice 15(5): 14-17

McClimens A and Scott R (2007) Lights, camera, education! The potentials of forum theatre in a learning disability nursing program. Nurse Educ Today 27(3): 203-9

Middlewick Y, Kettle TJ and Wilson JJ (2012) Curtains up! Using forum theatre to rehearse the art of communication in healthcare education. Nurse Educ Pract 12(3): 139-42

National Leadership and Innovation Agency for Healthcare (2010) Guidance on Involving Adult NHS Service Users and Carers. Llanharan: National Leadership and Innovation Agency for Healthcare

Oflaz F, Meric M, Yuksel C and Ozcan CT (2011) Psychodrama: an innovative way of improving selfawareness of nurses. J Psychiatr Ment Health Nurs 18(7): 569-75

Porter A and Tousman S (2010) Evaluating the Effect of Interactive Audience Response Systems on the Perceived Learning Experience of Nursing Students. Journal of nursing education 49(9): 523-527 
TITLE: Turning a crisis into an interactive drama: The introduction of a 'Clickers Theatre' in nurse education.

Tevendale F (2015) Using patient storytelling in nurse education. Nursing times 111(6): 15-17

Van Ments M (1999) The effective use of role play. London: Kogan Page

Welsh Assembly Government (2008) Stronger in Partnership 2: Involving Service Users and Carers in the design, planning, delivery and evaluation of mental health services in Wales. Welsh Assembly Government

Wilson JJ (2013) Let's all play 'Stigma'! Learning together using forum theatre in collaboration with mental health service users and nurse lecturers. Working papers in Health Sciences 1(4): 1-5 
TITLE: Turning a crisis into an interactive drama: The introduction of a 'Clickers Theatre' in nurse education.

Highlights

- An innovative interactive theatre method enacting service user narratives

- Combines a theatre based approach with an electronic student response system

- Method offers students chance to analyse clinical decision making in a classroom

- Enhancing the learning experience through students teaching students 